\title{
O EMPREGO DE FIGURAS RETÓRICAS DE INTERRUPÇÃO E SILÊNCIO EM JOSÉ MAURÍCIO NUNES GARCIA
}

\section{THE USE OF RHETORICAL FIGURES OF INTERRUPTION AND SILENCE IN JOSÉ MAURÍCIO NUNES GARCIA}

\author{
Eliel Almeida Soares \\ Universidade de São Paulo \\ elielasoares@yahoo.com.br \\ Rubens Russomanno Ricciardi \\ Universidade de São Paulo \\ rubensricciardi@gmail.com
}

\section{Resumo}

Este trabalho teve como objetivo expor alguns exemplos do emprego de figuras retóricas de interrupção de silêncio em José Maurício Nunes Garcia. Para isso, utilizou-se de métodos de análise adequados em conformidade ao texto, harmonia e ordenação do discurso musical. Os resultados alcançados por intermédio desse estudo serão demonstrados ao longo do trabalho.

Palavras-chave: Figuras Retóricas, Análise Musical, José Maurício Nunes Carcia, Musica Colonial Brasileira.

\section{Abstract}

This work aimed to expose some examples the use of rhetorical figures of interruption and silence in José Maurício Nunes Garcia. To achieve this objective, it was used appropriate analytical methods in accordance to the text, harmony and arrangement of the musical discourse. The results achieved through this study will be demonstrated throughout the work.

Keywords: Rhetorical Figures, Musical Analysis, José Maurício Nunes Carcia, Brazilian Colonial Music. 


\section{Lista de Figuras}

Figura 1: Abruptio no $1^{\circ}$ Responsório do Ofício dos Defuntos (1816)- comp.11-12.

Figura 2: Abruptio no Gloria da Missa de São Pedro de Alcântara (1809) - comp.71.

Figura 3: Abruptio no Popule Meus - comp.8.

Figura 4: Aposiopesis no $1^{\circ}$ Responsório do Ofício dos Defuntos (1816) - comp.13.

Figura 5: Aposiopesis no $1^{10}$ Responsório do Ofício dos DefuntosResponsórios de Matinas - comp. 13.

Figura 6: Aposiopesis no $4^{10}$ Responsório do Ofício dos DefuntosResponsórios de Matinas - comp.2,4 e 7.

Figura 7: Pausa no $1^{\circ}$ Responsório do Ofício dos Defuntos (1816)- comp.4.

Figura 8: Pausa no $1^{\circ}$ Responsório das Matinas e Encomendação de Defuntos- comp.3.

Figura 9: Pausa no Kyrie da Missa de São Pedro de Alcântara (1809)- comp.12-18.

Figura 10: Suspiratio no $6^{\circ}$ Responsório do Moteto Ascendens Christus (1809)-( $1{ }^{\circ}$ Movimento)-comp. 36-46.

Figura 11: Suspiratio no $6^{\circ}$ Responsório do Moteto Ascendens Christus (1809)-(2 Movimento)-comp. 85-93.

Figura 12: Suspiratio na $6^{\circ}$ Sinfonia Fúnebre-comp. 105- 109. 


\section{Introdução}

Indispensável para a formulação e elaboração de um discurso, a retórica é o instrumento de persuasão que auxilia o orador em convencer - público favoravelmente à sua tese, seja por intermédio da dialética ou conforme Hilton Japiassú e Danilo Marcondes "por sua habilidade em empregar a linguagem como recurso de persuasão e eloquência, com o propósito de despertar os afetos do ouvinte" (JAPIASSÚ; MARCONDES, 200 I, p. 235). Esse axioma, igualmente foi usado, de acordo com Soares "em muitas músicas do final do século XVI e começo do século XIX, com a finalidade de tornar claro e evidente o ordenamento do discurso musical" (SOARES, 2018, p.76-77). Em outras palavras, sua finalidade era a obtenção de um resultado eficaz e satisfatório tanto em seu desempenho como das audições. Para isso, fez-se necessário a utilização de vários mecanismos, por exemplo, metáforas, alegorias, relação entre texto e música, isto é, harmônica, motívica e semântica, trabalhados diligentemente em consonância com as figuras retórico-musicais.

Isto é, como verificado em Soares, Novaes e Machado Neto (2012), essa vinculação entre retórica e música pode ser examinada desde 0 início da Antiguidade greco-romana, onde diversos filósofos e pensadores estabeleciam relações de conceito entre si (SOARES; NOVAES; MACHADO NETO, 2012, p.30l). Ulteriormente, na ldade Média, no qual os padrões instaurados pelos teóricos da Antiguidade apresentaram-se essenciais para a efetivação da retórica como disciplina, a qual foi transmitida e associada à educação, por meio da universidade, semelhantemente difundido pela música renascentista, sob a perspectiva humanística, culminando no Barroco, na qual as distintas teorias sobre a retórica mostram-se fundamentais, para embasar os diversos tratados dos pensadores musicais na produção e elaboração da terminologia Musica Poetica, o qual indicava uma sistematização e teorização da música como discurso. Finalmente, no Classicismo, onde alguns gêneros e estilos composicionais preservaram essa tradição (SOARES, 2017, p.48).

Seguidor dessa prática, José Maurício Nunes Garcia (1767-1830) demonstrou a influência da retórica, disciplina estudada por ele desde sua juventude, tanto na arte da oratória como em suas composições, como ressalta Cleofe Person de Mattos: 
No mesmo período aplicava-se José Maurício a estudos de retórica, o que Salvador José também confirma. Explicase, portanto, fosse apontado como Orador pelo deão da Sé, no processo de genere. Estudo que se verifica de insuspeitada significação na personalidade do músico, que voltará a estudá-la, entre 1802 a 1804 [grifos nossos] (MATTOS, 1997, p.33-34).

Da mesma maneira, conforme Marcelo Fagerlande (1993) em seu Methodo de Pianoforte (1821), o padre José Maurício, expressa as mesmas concepções estéticas e conceituais originárias das doutrinas gregas e latinas de retórica e oratória, embasadas em autores como Aristóteles (384 a.C.-322 a.C.), Marco Túlio Cícero (106 a.C.- 43 a.C.), Marco Fábio Quintiliano (35-95), Marin Mersenne (1588-1648), Athanasius Kircher (1601-1680), Wolfgang Caspar Printz (1641-1717), entre outros. Não obstante, "emprega no ordenamento das tonalidades das lições de seu método, conotações semelhantes às usadas por tratadistas retórico-musicais como Johann Mattheson (1681-1764) e Christian Friedrich Daniel Schubart (1739-1791)" (FACERLANDE, 1993, p. 1 46).

Enfim, a utilização desses recursos retóricos na música dos séculos supracitados, despertou o interesse da atual das áreas da musicologia, teoria/análise e performance em investigar os processos de concepção e constituição dos elementos de retórica, contribuindo desse modo para o entendimento da disposição do discurso musical. Em vista disso, cumpre esclarecer que neste trabalho uma versão revisada, ampliada e atualizada do originalmente publicado nos anais da III Jornada Acadêmica Discente do Programa de Pós-Craduação em Música da Escola de Comunicações e Artes da Universidade de São Paulo (PPCMUS/ECA/USP) de 26 a 27 de Novembro de 2015, será exposto o emprego de figuras retóricas de interrupção e silêncio em José Maurício Nunes Carcia, utilizando-se métodos analíticos adequados, em conformidade ao texto, harmonia e ordenação do discurso musical, os quais serão expostos através das análises e exemplos, a seguir. 


\section{As cinco fases retóricas e o ordenamento do discurso musical}

Antes de examinar os exemplos analíticos das obras de José Maurício Nunes Garcia, para melhor entender como é disposto o discurso musical, além do modo de o autor trabalhar cada elemento retórico, é importante enfatizar que Johann Mattheson (1681-1764), em sua obra - mestre de capela perfeito (Der vollkommene Capellmesiter) (1739), expõe um parâmetro composicional balizado nas doutrinas retóricas, o que incitaria no enunciado musical resultado e eficácia semelhantes aos da arte da oratória. Evidentemente, fundamentado nos cânones clássicos, estabelece através das Cinco Fases Retóricas, uma relação convergente entre música e o discurso detalhado por George Buelow da seguinte maneira:

- Inventio - nela acontece a descoberta das ideias e dos argumentos que sustentarão a tese do orador, seja no ato de elaborar, nas ideias musicais, entre outros.

- Dispositio-nessa fase são ordenadas e distribuídas as ideias e argumentos localizados na Inventio.

- Elocutio - refere-se ao estilo. Aqui são constituídos os procedimentos de cada ideia, para o desenvolvimento de cada item e da sua ornamentação, é do mesmo modo conhecida por Decoratio ou Elaboratio.

- Memoria - onde são utilizados os diferentes modos e processos para memorizar o discurso; também, é a forma de operação de cada uma das fases retóricas.

- Pronuntatio - última fase retórica, no qual é proferido o discurso. Igualmente denominada, como Actio ou "ação" (atuação) diante do publico, ou seja, sua performance (BUELOW, 200 l, p.261).

Alusivo à Dispositio, Buelow disserta que alguns autores como Callus Dressler (1533-1589), efetuaram uma interpretação dessa fase de forma simplificada, em três partes (Exordium, Medium e Finis). Todavia, analogamente aos cânones clássicos, Mattheson as distribui em seis partes, desta forma: 
- Exordium - início do discurso;

- Narratio - declaração ou narração dos acontecimentos;

- Propositio ou Divisio - exemplificação da tese fundamental, aqui o conteúdo e objetivo do discurso musical se dão de maneira sucinta;

- Confutatio - refutação aos argumentos expostos. Nessa parte se localizam as ideias contrárias;

- Confirmatio - confirmação da tese inicial;

- Peroratio - conclusão. (BUELOW, 200 1, p.262).

\section{Análises e exemplos de figuras retóricas de interrupção e silêncio}

\section{Abruptio}

Como figura retórica de interrupção e silêncio, a Abruptio é empregada segundo Mauritius Johann Vogt (1669-1730) "num trecho musical onde ocorre uma interrupção abrupta por meio de algumas pausas" (BARTEL, 1997, p.169). No presente excerto do $1^{10}$ Responsório do Ofício dos Defuntos, de 1816, é verificável essa interrupção súbita e inesperada no meio e no final de expressão et in novissimo die de terra surrecturus sum (e que no último dia eu hei de ressuscitar da terra), nos compassos 11 e 12, caracterizando, assim, o uso desse recurso retórico. 


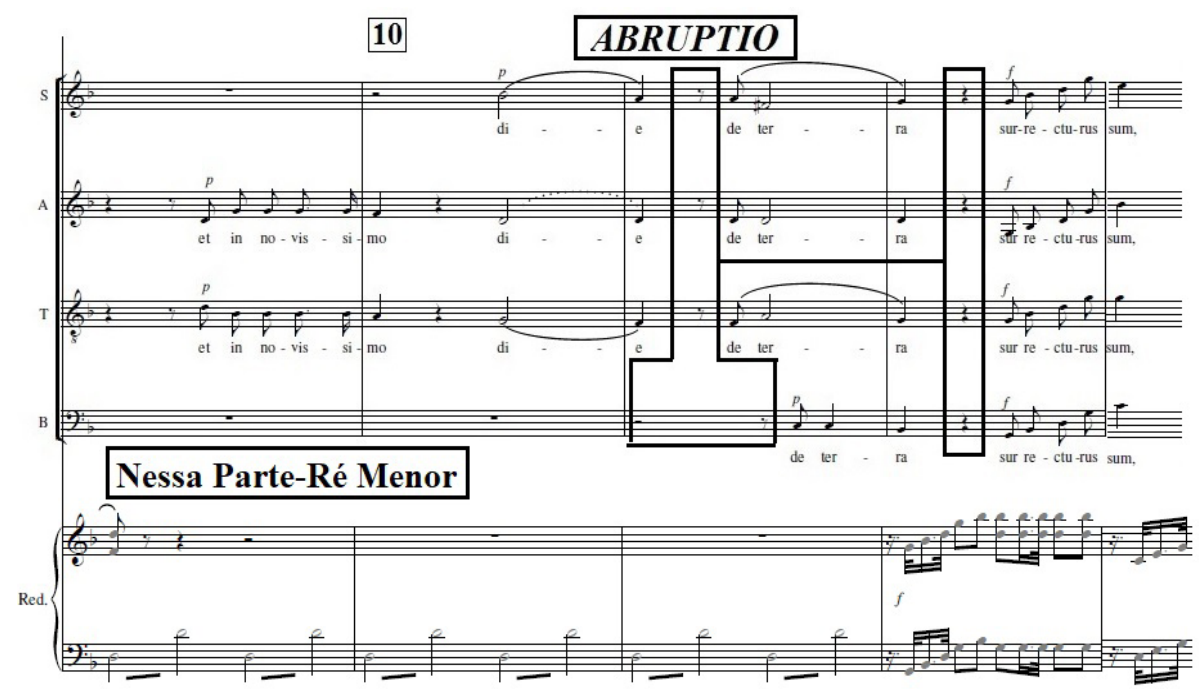

Figura 1: Abruptio no $1^{\circ}$ Responsório do Ofício dos Defuntos (1816)-comp. |1-12. Edição: Cleofe Person de Mattos (GARCIA, 1982, p.3).

O texto do Cloria da Missa de São Pedro de Alcântara é fundamento em Lucas 2: I 4, o qual versa sobre a proclamação dos anjos trazendo as boas novas, com grande congraçamento para os povos, do nascimento de Cristo, o Senhor e Redentor, em forma de júbilo e louvor. Esse afeto é destacado pelo autor mediante o uso da Abruptio, onde o final da expressão gloriam tuam: (vossa imensa glória) é interrompida de maneira inesperada por meio da Cadência de Engano, assim como, todas as vozes e o acompanhamento instrumental, no compasso 71 . 


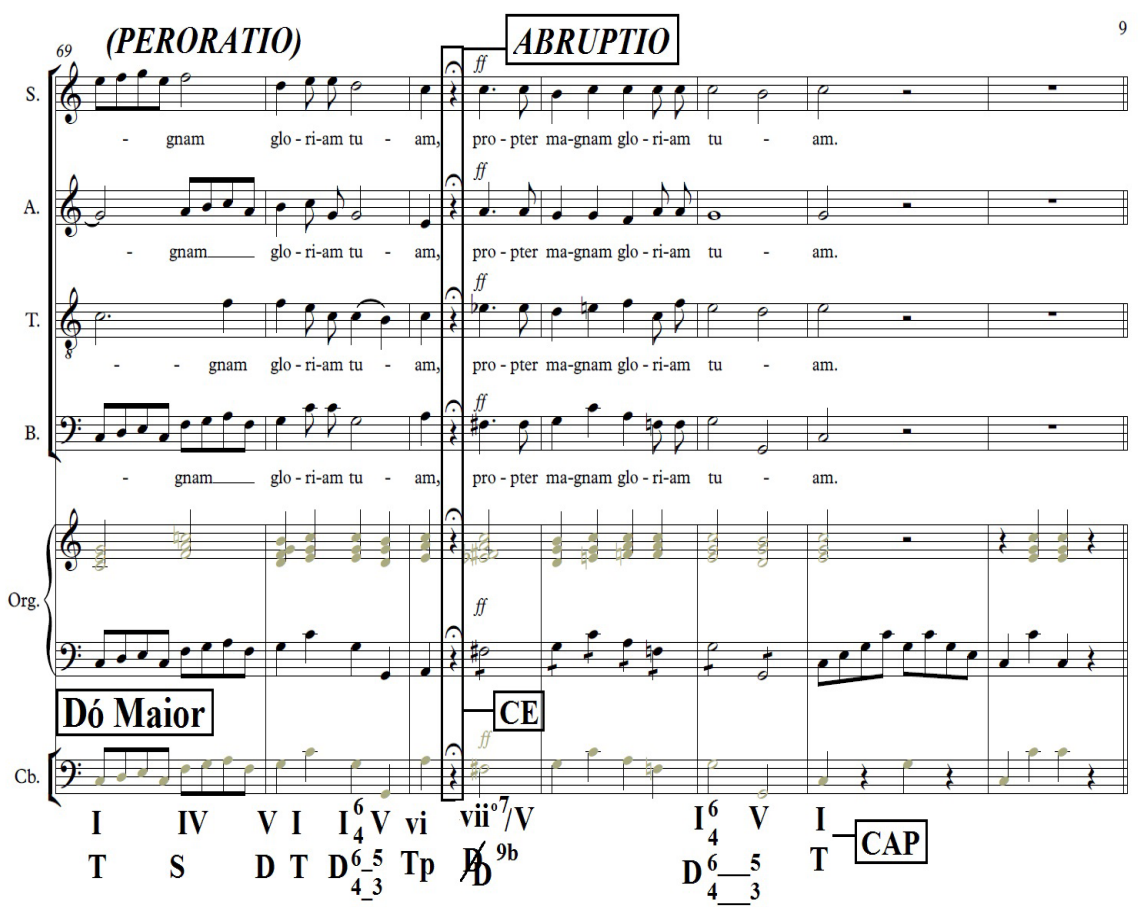

Figura 2: Abruptio no Gloria da Missa de São Pedro de Alcântara (1809) - comp.71. Edição: Cleofe Person de Mattos (GARCIA, s/d, p.9).

Verifica-se no Popule Meus, parte constituinte dos dísticos do Rito Romano', entoados em forma de antífona, seguidos de respostas alternativas gregas e latinas, o uso da Abruptio para destacar tanto a repetição da frase quid feci tibi (o que Eu fiz para vocês?), por meio da interrupção do trecho final com pausas como na Semicadência, valorando as funções das Dominantes secundárias e Dominante na transição dos compassos 7 para $\circ 8$.

Esses na maioria das vezes são formados por estrofes pequenas, tendo dois versos. 


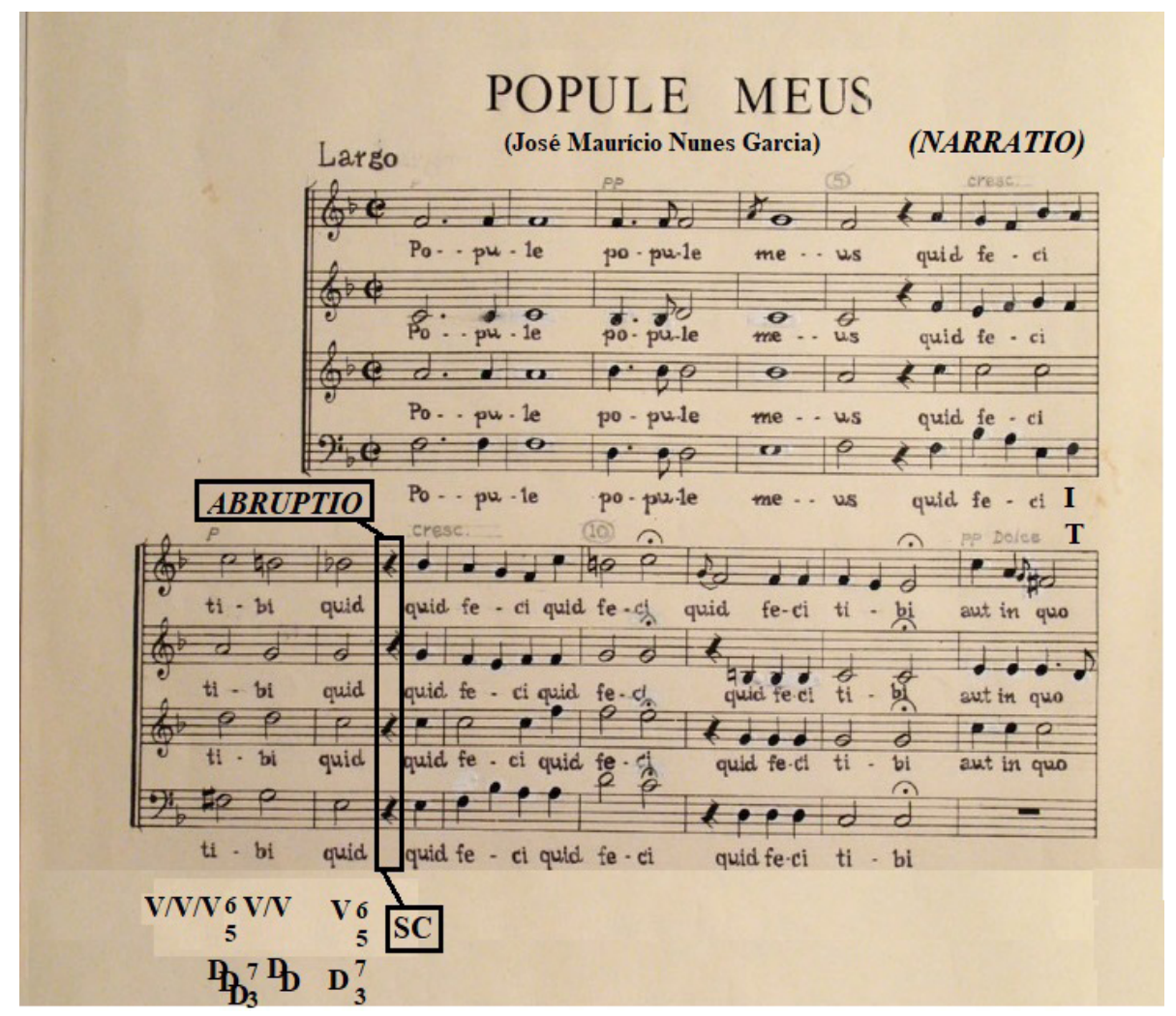

Figura 3: Abruptio no Popule Meus - comp.8. Edição: Cleofe Person de Mattos (CARCIA, s/d, p. 1).

\section{Aposiopesis}

Johann Gottfried Walther (1684-1748) ressalta que "a Aposiopesis é uma pausa geral, isto é, um completo silêncio em todas as vozes e nas partes da composição simultaneamente" (BARTEL, 1997, p.205). Nessa parte do $1^{\circ}$ Responsório do Ofício dos Defuntos de 1816, observase que José Maurício Nunes Carcia, aplica a Aposiopesis nas quatro vozes no compasso 13, impondo um silêncio total, além de enfatizar à expressão die de terra surrecturus sum (hei de ressuscitar da terra) que é repetida em estrutura cordal. Também, no compasso 16, verifica-se que esse elemento retórico de interrupção e silêncio valora tanto a 
dinâmica fortíssimo, a linha fraseológica como as funções harmônicas da Dominante e Tônica e, com conclusão na Cadência Autêntica Perfeita.

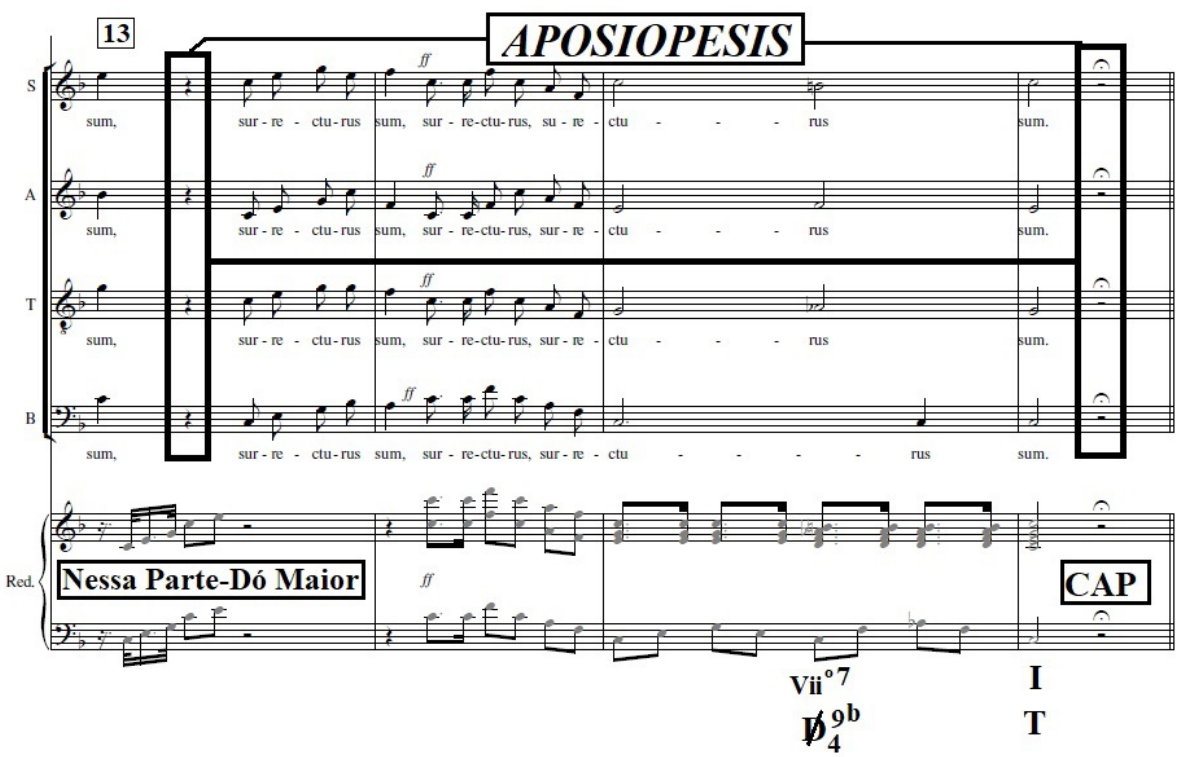

Figura 4: Aposiopesis no $1^{\circ}$ Responsório do Ofício dos Defuntos (1816)- comp.13. Edição: Cleofe Person de Mattos (CARCIA, 1982, p.4).

Pode-se constatar o uso da Aposiopesis, através da pausa geral em todas as vozes, no compasso 13, valorando, assim, a expressão et in novissimo die de terra surrecturus sum (no último dia eu hei de ressuscitar [subir, levantar] da terra), por meio de alternâncias das dinâmicas, forte, piano e crescendo, produzindo um efeito sonoro e de suspenção, resolvendo em uma Cadência na Dominante. 


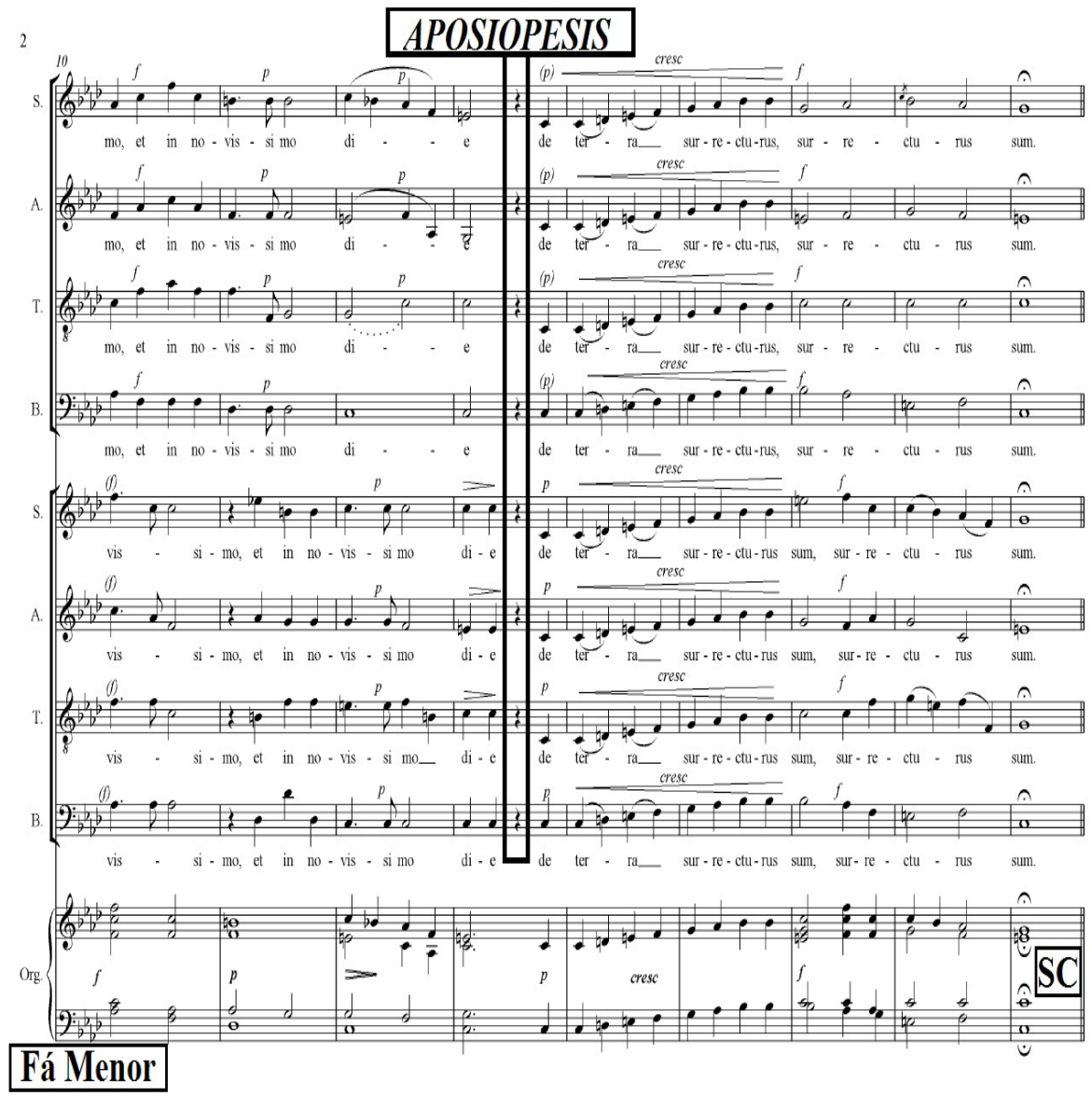

Figura 5: Aposiopesis no $1^{\circ}$ Responsório do Ofício dos Defuntos-Responsórios de Matinas - comp. 13. Edição: Cleofe Person de Mattos (CARCIA, s/d, p.2).

Examina-se o emprego da mesma figura no exemplo abaixo, entre os compassos 2,4 e 7, na qual a repetição melódica e das palavras memento mei, Deus (Lembrai-Vos de mim, Senhor), além da reiteração melódica em alturas diferentes, resolvendo depois na Cadência Autêntica Imperfeita, evidencia o afeto de angústia e languidez, descrito em Jó 7:7: "Lembra-te, ó Deus, de que a minha vida não passa de um sopro; meus olhos jamais tornarão a ver a felicidade" (ALMEIDA, 2000, p.727). 


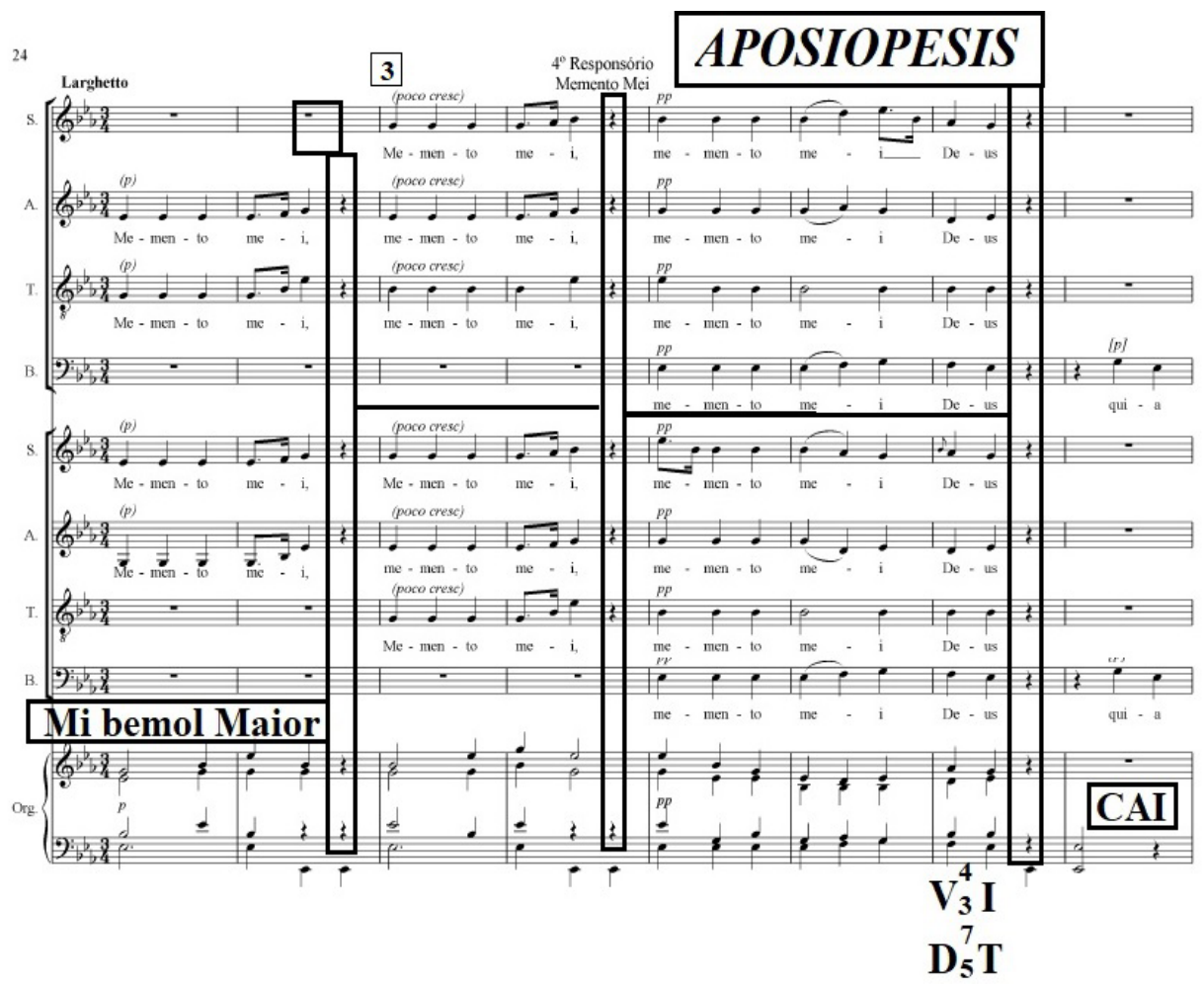

Figura 6: Aposiopesis no $4^{\circ}$ Responsório do Ofício dos Defuntos-Responsórios de Matinas- comp.2,4 e 7 .

Edição: Cleofe Person de Mattos (CARCIA, s/d, p.24).

\section{Pausa}

De acordo com Soares "O texto do Ofício dos Defuntos é embasado na passagem bíblica localizada em Jó 19:25" (SOARES, 2014 , p.9). Verifica-se que o discurso desse excerto se inicia de modo afirmativo e enfático com uma declaração do personagem bíblico Jó: Credo quod Redemptor meus vivit (Creio que o meu redentor vive). Destarte, tal louvor é ratificado e consolidado na transição do Exordium para a Narratio, onde Nunes Carcia usa a Pausa em todas 
as vozes para separar a frase em uma função não esperada, ou seja, na Subdominante. Corroborando assim, com a afirmação de Walther, de que esse elemento retórico representa "um período de repouso ou silêncio na música, em outras palavras, através de um determinado sinal e valor é indicado o descanso necessário numa parte da composição musical" (BARTEL, 1997, p.365).

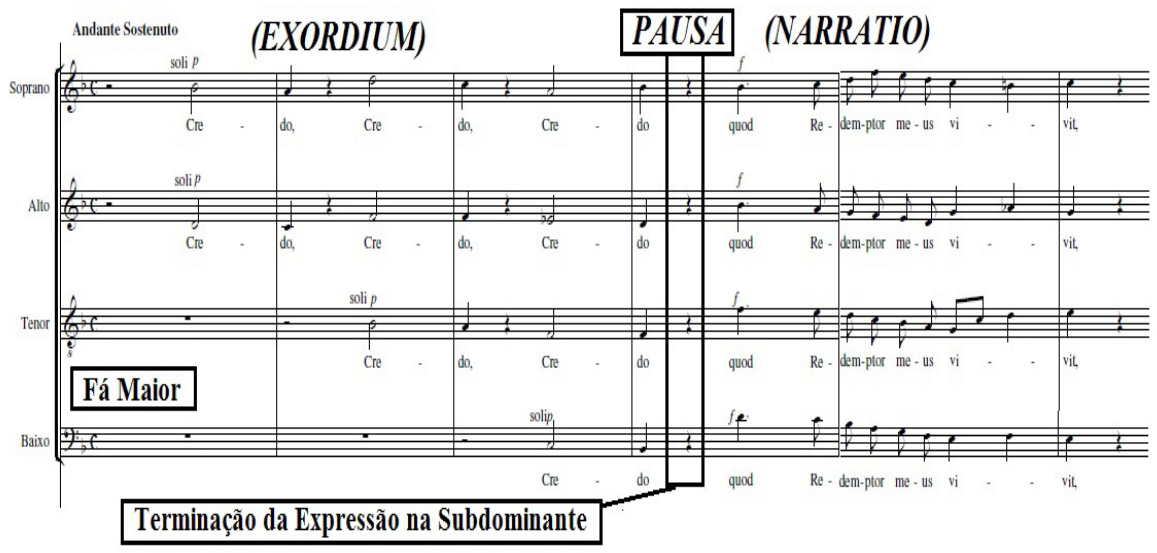

Figura 7: Pausa no $1^{\circ}$ Responsório do Ofício dos Defuntos (1816)- comp.4. Edição: Cleofe Person de Mattos (CARCIA, 1982, p.1-2).

Nesse trecho, nota-se que o mesmo texto e figura são utilizados pelo autor, porém, diferentemente do exemplo anterior, à separação da frase acontece depois das palavras Credo quod (Creio que). Do mesmo modo, há de se salientar os andamentos e tonalidades diferentes, por exemplo, o Ofício dos Defuntos, de 1816, está num Andante Sostenudo e tonalidade Fá Maior, já o das Matinas e Encomendação de Defuntos, encontra-se num Moderato e em Sol Menor finalizando com uma Cadência Autêntica Imperfeita. 
Matinas e Encomendação de Defuntos

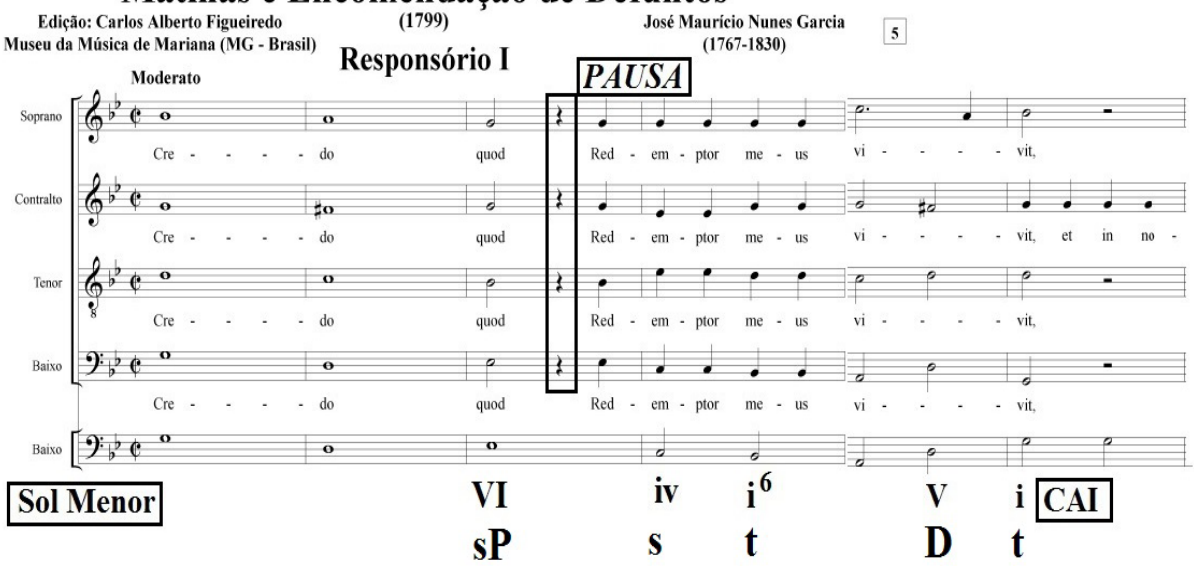

Figura 8: Pausa no $1^{\circ}$ Responsório das Matinas e Encomendação de Defuntos (1799) comp.3. Edição de Carlos Alberto Figueiredo (CASTACNA, 2003, p. I).

Na transição do Exordium para a Narratio do Kyrie da Missa de São Pedro de Alcântara, verifica-se o emprego da Pausa entre os compassos 12 e 18. Nota-se também, que esse elemento retórico de interrupção e silêncio realça as frases Kyrie eleison (Senhor, tende piedade de nós) e Christe eleison (Cristo, tende piedade de nós), além do solo da soprano e tenor, das dinâmicas, das funções harmônicas e do pedal de Tônica, através da nota Mi bemol. 
(EXORDIUM)

(NARRATIO)

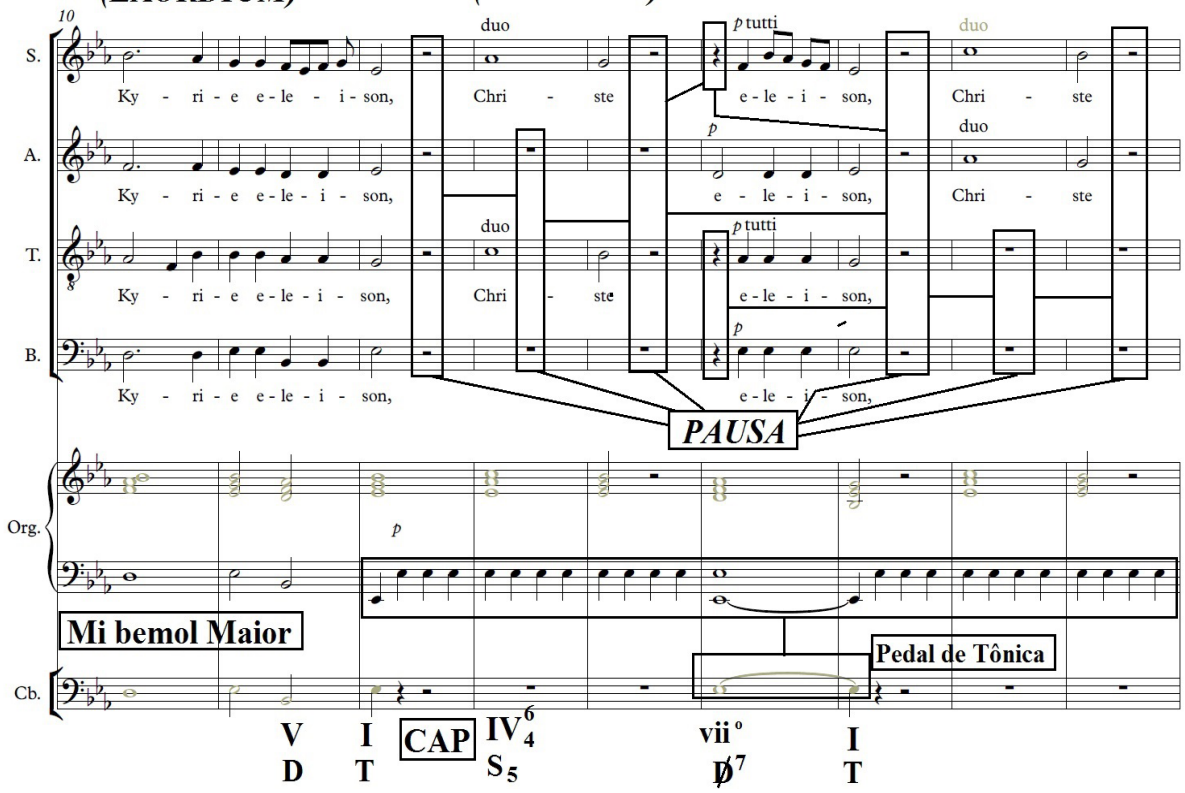

Figura 9: Pausa no Kyrie da Missa de São Pedro de Alcântara (1809)- comp. 12 - 18. Edição: Cleofe Person de Mattos (CARCIA, s/d, p. 1).

\section{Suspiratio}

Athanasius Kircher (1601-1680) enfatiza que: "A Suspiratio lembram os afetos naturalmente expressados por vários suspiros criados através de pausas" (BARTEL, 1997, p. 393-394). Fato esse, que pode observado no Moteto Ascendens Christus, através do uso da Suspiratio destacando a expressão Allelvia, repetida nessa passagem por cinco vezes. Além de criar um efeito sonoro, o autor trabalha com as dinâmicas piano e forte para destacar o afeto de devoção, exultação, júbilo do fiel, o qual baseado nos Salmos (Ps. 46:6/47:5)2, descrito dessa maneira: "O Senhor subiu entre as (aclamações) nações, ao som de trombeta. Alelvia".

2 Salmos 46:6 são o número e versículo na bíblia católica, já na bíblia protestante o texto está escrito no número 47 e versículo 5. 


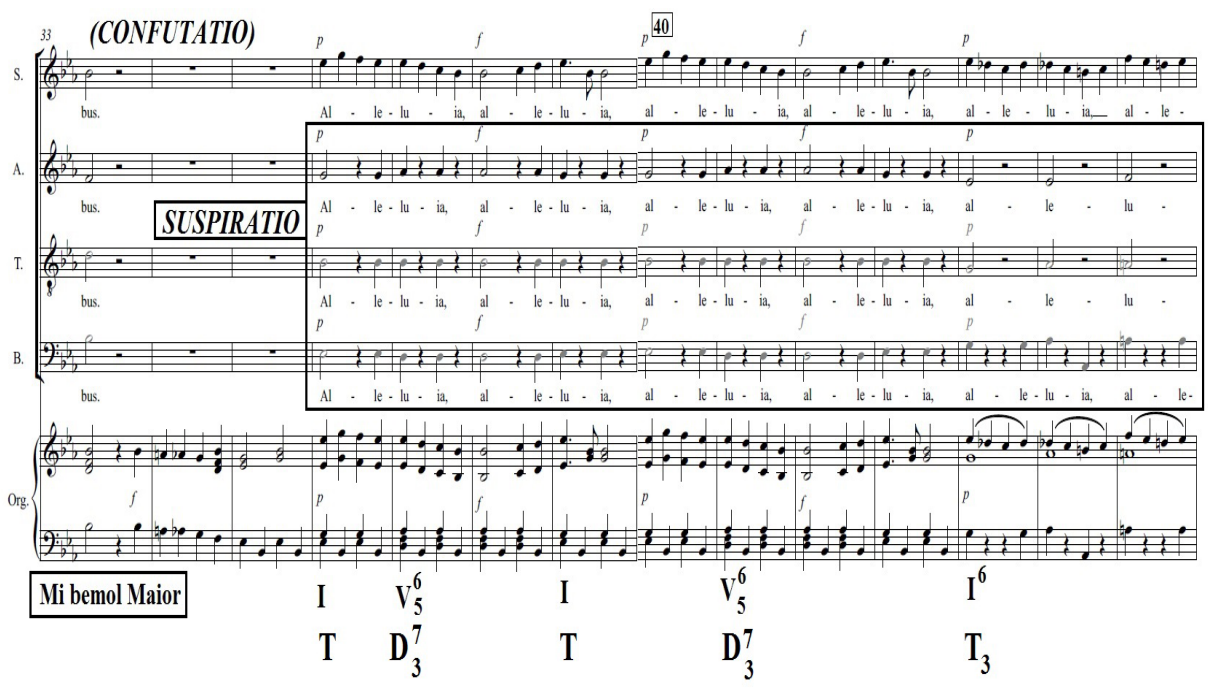

Figura 10: Suspiratio no $6^{\circ}$ Responsório do Moteto Ascendens Christus ( 1809$)$-( $1^{10}$ Movimento)-comp. 36-46. Edição: Cleofe Person de Mattos (CARCIA, s/d, p.9).

Ainda na mesma obra, é verificável a presença da Suspiratio destacando mais uma vez a expressão Allelvia, repetida nesse trecho por quatro vezes, entretanto, diferentemente da figura anterior, entoada somente pela voz do baixo, dando continuidade a ênfase do afeto de devoção e exultação, expressos pelo salmista. 


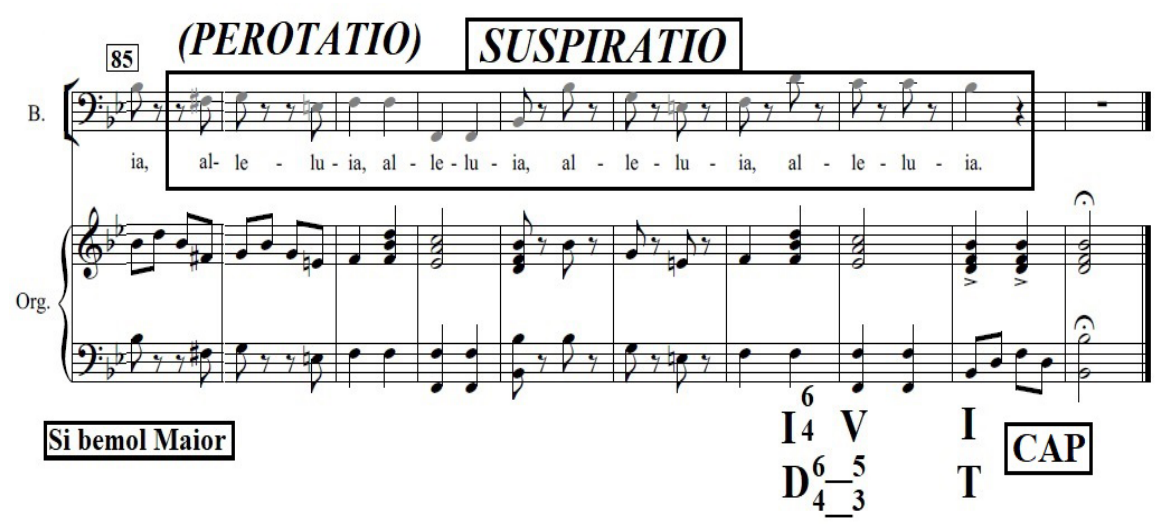

Figura 11: Suspiratio no $6^{\circ}$ Responsório do Moteto Ascendens Christus ( 1809)-(2 Movimento)-comp. 85-93. Edição: Cleofe Person de Mattos (CARCIA, s/d, p. 15).

Nota-se o emprego da mesma figura na Sinfonia Fúnebre do padre José Maurício, entre os compassos 105 e 109. De igual modo, é examinável que a Suspiratio destaca mediante as pausas além de todos os instrumentos da orquestra, as notas, as dinâmicas, os motivos rítmicos, além da função harmônica da Tônica resolvendo na Cadência Autêntica Imperfeita. 


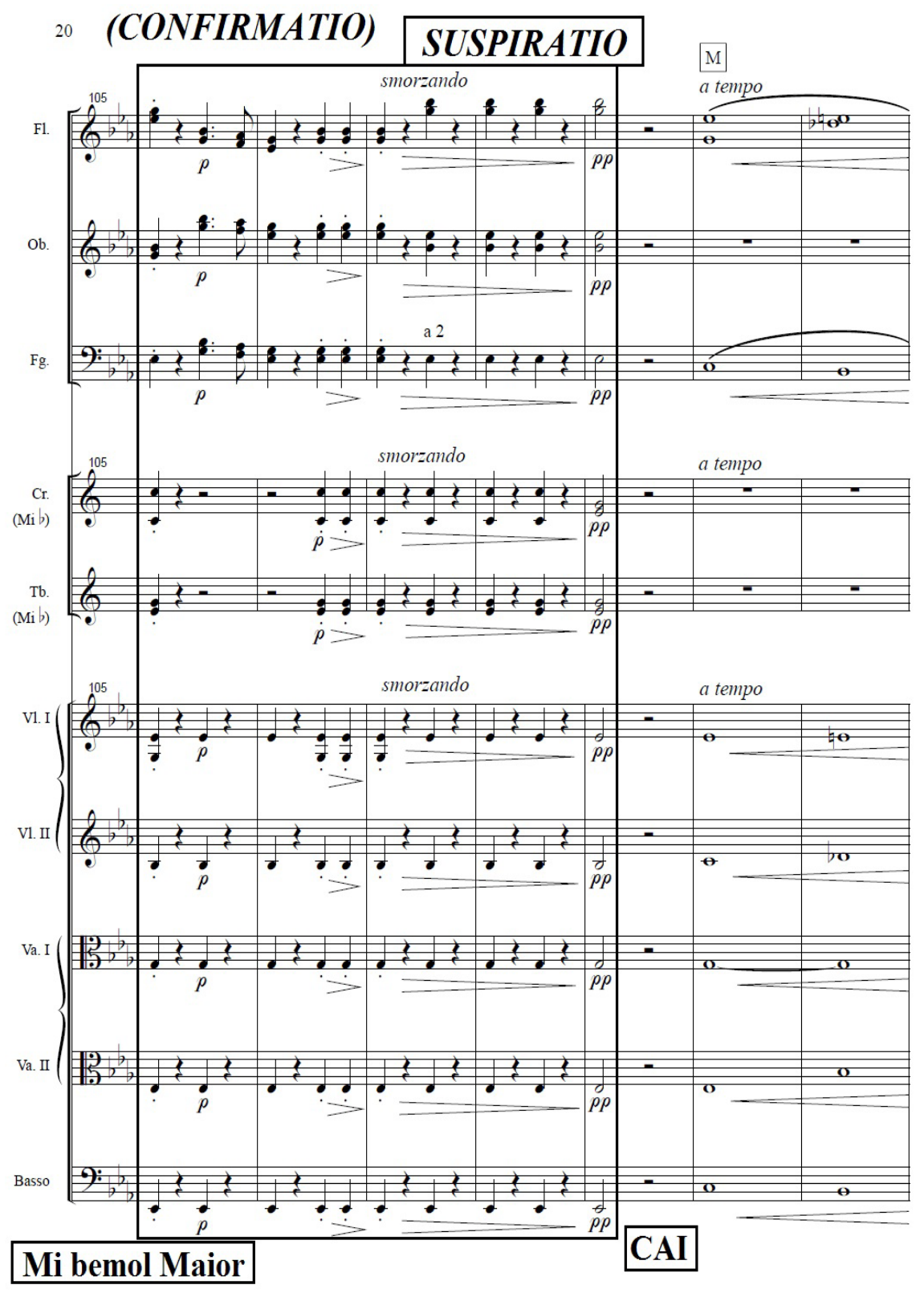

Exemplo 12: Suspiratio na $6^{\circ}$ Sinfonia Fúnebre (1790) - comp. 105- 109. Edição Crítica: Rubens Russomanno Ricciardi (RICCIARDI, 2018, p.20). 


\section{Considerações Finais}

Os mestres da composição usavam os elementos retóricos com o propósito de atrair a atenção do ouvinte, por intermédio da eloquência e persuasão. Para tanto, mecanismos como as figuras retóricas de interrupção e silêncio, foram aplicadas para auxiliar o autor não só na organização e ordenamento do discurso, mas, igualmente, na valoração das Cadências e harmonia, repetições, no realce das palavras, frases e, por fim, nos afetos trabalhados diligentemente objetivados em mover os sentimentos do público. Em outras palavras, esse recurso mostrava-se eficaz numa composição engenhosa, inter-relacionada com variadas partes estruturais, semânticas, textuais, motívicas, entre outras.

Ao examinar os exemplos das peças do mestre de capela da Sé do Rio de Janeiro, verificou-se o emprego de figuras e elementos de retórica, dispostos e ordenados, conforme a circunstância do discurso. Por exemplo, no Popule Meus realçando tanto a repetição da frase quid feci tibi (o que Eu fiz para vocês?), mediante interrupção do trecho final com pausas como na Cadência na Dominante. Do mesmo modo, no Gloria da Missa de São Pedro de Alcântara, para realçar a interrupção inesperada da frase gloriam tuam: (vossa imensa glória), por intermédio da Cadência de Engano, tanto nas vozes quanto do acompanhamento instrumental. No $1^{10}$ Responsório do Ofício dos Defuntos (1816), Nunes Carcia utiliza a Abruptio, para destacar as palavras in novissimo die de terra surrecturus sum (e que no último dia eu hei de ressuscitar da terra), interrompendo o trecho com inserção de pausas. De igual forma, observou-se que o compositor faz uso da Aposiopesis para impor um silêncio total a todos as vozes, bem como colocar em destaque a repetição da estrutura cordal, valorando assim, as dinâmicas, as frases e as funções harmônicas.

Ainda na mesma obra, observou-se o uso da Pausa, para separar a expressão Credo (Creio), além de servir de transição do Exordium para a Narratio. Tal figura, também pode ser verificada no $1^{\circ}$ Responsório das Matinas e Encomendação de Defuntos, onde o autor trabalha com o mesmo texto, entretanto, a figura oferece um momento de descanso somente depois da expressão Credo quod (Creio que). Finalmente, no Kyrie da Missa de São Pedro de Alcântara, na qual a Pausa é aplicada 
como a mesma finalidade, destacando a consonância das notas, do solo da soprano e tenor com as funções harmônicas.

Outro aspecto a ser enfatizado, é aplicação da Aposiopesis no $4^{\circ}$ Responsório das Matinas e Encomendação de Defuntos, a qual enfatiza mediante o silêncio de todas as vozes, a repetição das palavras memento mei, Deus (Lembrai-Vos de mim, Senhor), a resolução cadencial e o afeto de angustia e tristeza.

Por fim, o emprego da Suspiratio no $6^{\circ}$ Responsório do Moteto Ascendens Christus, ressaltando o afeto de exaltação e júbilo, através da expressão Alleluia e na Sinfonia Fúnebre, enfatizando as notas, os motivos musicais, as dinâmicas e as funções harmônicas.

Após essas observações, destacamos que um dos maiores desafios nesse campo investigativo é distinguir gestualidades das figuras dentro de uma categorização e ambiente comum a todos. Por essa razão, é necessário buscar constantemente um estudo mais minucioso e acentuado sobre questões da utilização dos recursos retórico-musicais, aumentando o número de exemplos para análise.

Em suma, nas 12 figuras observou-se que, José Mauricio Nunes Carcia dispõe esses recursos de modo articulado, ordenado e consciente, evidenciando, assim, possuir sólido conhecimento teórico, para embasar a utilização de elementos retóricos em suas obras.

\section{8}




\section{Referências}

ALMEIDA, João Ferreira de. Biblia de Estudo Shedd. São Paulo: Edições Vida Nova Cultura Cristã (Sociedade Bíblica do Brasil), 2000.

BARTEL, Dietrich. Musica Poetica: Musical-Rhetorical Figures in German Baroque Music. Lincoln: University of Nebraska Press, 1997.

CASTAGNA, Paulo Augusto. (Org.). Música fúnebre: Restauração e Difusão de Partituras. (Matinas e Encomendação de Defuntos de José Maurício Nunes Garcia-Edição de Carlos Alberto Figueiredo). $1^{\circ} \mathrm{E}$. Belo Horizonte: Fundação Cultural e Educacional da Arquidiocese de Mariana, v. 1, 2003.

FACERLANDE, Marcelo. O Método de Pianoforte de José Maurício Nunes Garcia. Rio de Janeira, 1993. 218 f. Dissertação (Mestrado em Musicologia). Conservatório Brasileiro de Música, Rio de Janeiro, 1993.

CARCIA, José Maurício. Ofício de Defuntos (1816). Edição: Cleofe Person de Mattos, Rio de Janeiro: FUNARTE, 1982.

Ascendens Christus Moteto para o Ofertório da Missa de $5^{a}$ feira de Ascenção (1809). Edição: Cleofe Person de Mattos. Rio de Janeiro, (s/d). Partitura. Disponível em: <http://www.josemauricio.com.br/ pdfs/cpm053_ascendens_christus.pdf $>$. Acesso em: 13 jul. 2018.

Missa de São Pedro de Alcântara (1809). Edição: Cleofe Person de Mattos. Rio de Janeiro, (s/d). Partitura. Disponivel em:< http://www.josemauricio.com.br/pdfs/cpm 105_missa_de_s_pedro_de_ alcantara.pdf >. Acesso em: 16 jul.2018.

Popule Meus. Edição: Cleofe Person de Mattos. Rio de Janeiro, (s/d). Partitura.

$1^{10}$ Responsório do Ofício dos Defuntos-Responsórios de Matinas. Edição: Cleofe Person de Mattos. Rio de Janeiro, $(\mathrm{s} / \mathrm{d})$. Partitura. Disponivel em: <http://www.josemauricio.com.br/pdfs/cpm |91_ oficio_a_8_vozes_0l_credo.pdf $>$. Acesso em $12 \mathrm{fev} .2019$.

$4^{\circ}$ Responsório do Ofício dos Defuntos-Responsórios de Matinas. Edição: Cleofe Person de Mattos. Rio de Janeiro, (s/d). Partitura. 
Disponivel em: $<$ http://www.josemauricio.com.br/pdfs/cpm 191_oficio_a_8_ vozes_04_memento_mei.pdf $>$. Acesso em $18 \mathrm{fev} .2019$.

JAPIASSÚ, Hilton; MARCONDES, Danilo. Dicionário Básico de Filosofia. $3^{\text {aE}}$ Ed. Rio de Janeiro: Editora Jorge Zahar, 2001.

MATTOS, Cleofe Person de. José Maurício Nunes Garcia: Biografia. Rio de Janeiro: Biblioteca Nacional, 1997.

RICCIARDI, Rubens Russomanno. Sinfonia Fúnebre de José Maurício Nunes Garcia (1790). Edição Crítica de Rubens Russomano Ricciardi. Partitura. Serviço de Edição e Difusão de Partituras do NAPCIPEM / FFCLRP-USP (Ribeirão Preto), 2018. Disponível em: $<\underline{\text { http:// }}$ ks 4.imslp.info/files/imglnks/usimg/8/88/IMSLP537299-PMLP868437Sinfonia_F\%C3\%BAnebre___Complete_Score.pdf>. Acesso em: 24 ago. 2018.

SOARES, Eliel Almeida. Retórica: um novo objeto de estudo na música colonial brasileira. In: SIMPÓSIO BRASILEIRO DE PÓS-CRADUANDOS EM MÚSICA, 3., 2014, Rio de Janeiro. Anais... Rio de Janeiro: Unirio, 2014. p. $1-11$. <http://www.seer.unirio.br/index.php/simpom/article/ download/4668/4167>. Acesso em: 23 mai.2018.

- Emprego da Retórica na Música Colonial Brasileira. 533f. Tese (Doutorado em Música) - Pós-Graduação em Música, Escola de Comunicações e Artes, ECA, Universidade de São Paulo, USP, São Paulo, 2017.

Exemplos de figuras retóricas no $1^{10}$ Responsório das matinas e encomendação de defuntos, de José Maurício Nunes Carcia. Revista da Tulha, v. 3, n.2, p. 75-94, 2018. Disponivel em: <https://www. revistas.usp.br/revistadatulha/article/view/137333/140084> Acesso em 17 fev.2019.

SOARES, Eliel Almeida; NOVAES, Ronaldo; MACHADO NETO, Diósnio. Retórica na música colonial brasileira: O uso da anaphora em André da Silva Comes. In: ENCONTRO DE MUSICOLOCIA DE RIBEIRÃO PRETO, 4., 2012, Ribeirão Preto. Anais... Ribeirão Preto: Laboratório de Teoria e Análise Musicais, 2012. p. 301-306. 


\section{Sobre os autores}

Eliel Almeida Soares é graduado em Música (2008), Mestre (2012) e Doutor (2017) em Musicologia pelo Departamento e Programa de Pós-Graduação em Música da Escola de Comunicações e Artes da Universidade de São Paulo (ECA/USP). Desenvolveu com apoio financeiro da bolsa de doutorado da Fundação de Amparo à Pesquisa do Estado de São Paulo (FAPESP-Processo n $2013 / 23600-3$ ), pesquisas sobre as estruturas discursivas na música colonial brasileira. Também possui diversos trabalhos publicados sobre retórica musical. Atualmente faz parte do Núcleo de Pesquisa em Ciências da Performance em Música do Departamento de Música da Faculdade de Filosofia, Ciências e Letras de Ribeirão Preto da Universidade de São Paulo (NAP-CIPEM/DM/ FFCLRP/USP), onde desenvolve seu pósdoutoramento sob a supervisão do Prof. Dr. Rubens Russomanno Ricciardi.

Rubens Russomanno Ricciardi é compositor, maestro, pianista e musicólogo. Graduado em Música (1985), Mestre em Musicologia (1996), Doutor em Musicologia (2000) pelo Departamento de Música e Programa de Pós-Graduação em Música da Escola de Comunicações e Artes da Universidade de São Paulo (ECA/USP) e Livre-Docente em Teoria e Análise (2003) pela mesma instituição. Fundador, professor titular e decano do Departamento de Música da Faculdade de Filosofia, Ciências e Letras de Ribeirão Preto da Universidade de São Paulo (DM-FFCLRP/USP), onde fundou e dirige a USP-Filarmônica, o Centro de Memória das Artes, o Núcleo de Pesquisa em Ciências da Performance em Música (NAP-CIPEM). Professor responsável pelo Festival Música Nova "Gilberto Mendes" e pelo projeto USP-Música.

Recebido em 16/04/2019

Aprovado em 01/08/2019 